\title{
Formation of Sustainable Development Science: Situation, Problem, Method and Object
}

\author{
${ }^{1}$ Gabibulla R. Khasaev, ${ }^{2}$ Marina Y. Sadovenko, ${ }^{3}$ Roman O. Isaev, ${ }^{4}$ Vladislav V. Kharizin \\ ${ }^{1}$ Department of Regional Economics and Management, Samara State University of Economics, Samara, Russian, \\ Federation, ${ }^{2}$ Corporation “Cultural Russia, Holy Ground”, Samara, Russian Federation, ${ }^{3}$ Department of \\ Philosophy, Samara National Research University, Samara, Russian Federation, ${ }^{4}$ Department of Linguistics and \\ Philology, Samara National Research University, Samara, Russian Federation \\ Email: ${ }^{1}$ gr.khas@mail.ru, ${ }^{2}$ sadovenko14@gmail.com, ${ }^{3}$ romanceisaev@gmail.com; ${ }^{4}$ vlad-harizin@mail.ru
}

\section{Received: $6^{\text {th }}$ June 2018, Accepted: 28 $^{\text {th }}$ March 2018, Published: 30 $^{\text {th }}$ April 2018}

\begin{abstract}
In this paper we wanted to substantiate the historical "request" of creating a sustainable development science. This situation is directly related to the problem of the relationship between culture and science. We have proven that the "metaphysical perception" of sustainable development is defined by the culture of international organizations. We affirm that research knowledge of the process of sustainable development is not formed due to the lack of a scientific subject. The current relationship between philosophy and scientific methodology allows us to choose the "ontology" and "method" for forming sustainable development science. We believe that the task of transferring the practical phenomena classified as "sustainable development" into the classical forms of scientific knowledge will happen in the near future. We reconstructed the philosophical concept of "ontology" and studied it as the methodological creation tool of sustainable development science. Choosing a name for sustainable development science attracts the resources of both semantics and semiotics. We wanted to differentiate the objects of ecology and sustainable development science and used the means of the systematic approach. Philosophy has provided our research with the method of "reflective analysis". We clarified its modern function in science. Reflective analysis solves the problem of the creation of "transformed" scientific forms (models and knowledge) on the material of heterogeneous practices of sustainable development. In this article we present the first systematic definition of the object of sustainable development science. We consider "biosphere reserve" and "urban agglomeration" to be the "starting" areas of the case study of sustainable development.
\end{abstract}

Keywords: Sustainable Development Science; Ontology; Reflective Analysis; Definition of the Object

\section{Introduction}

The modern scientific world views the process of evolution in the context of biological sciences. We affirm the possibility of expanding the scope of the study of evolutionary processes Evolution can be seen as a reality that includes not only the world of living organisms, but also the universe of human activity. We propose to interpret sustainable development as a not yet studied evolutionary process of the noosphere (Le Roy, 1931; Teilhard, 1959; Vernadsky, 1944) [1-3]. Sustainable development is a "young" evolutionary process. It takes place on a material non-specific to biology. The peculiarity of sustainable development is the fact that it organizes life, nature, mind, society. What differentiates sustainable development from traditional evolutionary processes is the artificial component. We affirm that since the beginning of the 21 st century sustainable development has real manifestations: technological, organizational and social. But the contents and form of this process remain unnoticed, eclipsed by the popularity of ecology and philosophy of environmental protection. Leading theorists have made evolutionary process conclusive. They formed such operational scientific concepts as "elementary evolutionary unit" and "elementary evolutionary phenomenon." Representatives of paleontology passionately criticize evolutionary theory (Stahl, 1974; Lewin, 1981) [4, 5].

We affirm that sustainable development is the manifestation of evolution on the system level of the noosphere. Creating sustainable development science is an expansion of the general philosophical framework of knowledge of evolution.

\section{Background}

By "purpose" of the work we meant the designation of the historical and cultural situation that points to the timeliness of sustainable development science.

By "objectives" of the work we meant theoretical steps. The first step is describing the formation method of sustainable development science. The second step is the choice of ontology for sustainable development science. The third step is the definition of the object of the sustainable development science.

"The creation of new science" is a process not familiar to the modern period of the use of scientific knowledge. The cases of transformation of various systems of scientific knowledge into modern consumer goods or services have become commonplace. There is a tendency to protest against 
the capture of traditional cultural areas, including a person's life and values, by scientific concept forms (Rip, 2006) [6].

Sustainable development is one of the few areas that has formed in the culture, but didn't claim scientific resources for its own development. The criterion for registering any human action in science is the existence of the "standard model" best exemplified by atomic physics or organic chemistry (Peierls, 2006) [7]. There is no "standard model" for sustainable development though. This allows us to re-examine the current standing of sustainable development and to make a historical reconstruction of its constituent concepts.

Our applied research on "Biosphere reserve - a systematic study of the processes of social, economic and environmental development" has allowed us to establish the area that caters to the popular concept of "sustainable development". This area is the culture of international relations.

Research of the biosphere reserve was carried out in a "functional studies" manner. This means that the biosphere reserve was not regarded as a "natural object". We determined the functions of the concept of "biosphere reserve" and the scope of its generation and consumption. This concept originated in the process of the formation of UNESCO's environmental position in the late 1960's. Originally, UNESCO's competences were the areas of "culture" and "education". They were joined by unique natural areas designated by the "biosphere reserve" regulatory unit. The notion of "biosphere reserve" historically developed on the basis of UNESCO's goals supported by the ideology of sustainable development (UNESCO Seville Strategy, 1996) [8]. Just like "cluster" in M. Porter's theory of economics (Porter, 1998) [9], "biosphere reserve" dealt with a task unusual for the traditional concept of the object. "Cluster" allowed us to think about competition at the national level. "Biosphere reserve" gave us the opportunity to understand the network organization of the biosphere conservation culture. The biosphere protection culture included not only nature but society as well.

In the applied research on the topic "Biosphere reserve - a systematic study of the processes of social, economic and environmental development," we got a special theoretical "fact". It established the connection between the two concepts of "biosphere reserve" and "sustainable development" in UNESCO's work. This result indicates the following objective situation: "Sustainable development is a private paradigm and element of the culture of international relations." This link between sustainable development and culture was not accidental. UNESCO's profile involves treating any objects (including natural) as objects of culture. "Reinforced preservation", the main type of relationship promoted by UNESCO, completely coincided with the ideas of sustainable development. The history of the changes of the concept of "biosphere reserve" serves as a demonstration of shaping into forms of international relations culture.

This objectification of functions of sustainable development explained the modern "manipulation" on the part of international organizations in relation to industrial manufacturers. Special "rules" that limited the side effects of civilization processes began "falling out" out of the sustainable development culture. An example of such rules is the size of the maximum allowed concentration of $\mathrm{CO} 2$ in the atmosphere (Commission plans legislative framework to ensure the EU meets its target for cutting CO2 emissions from cars in 2007) [10]. The culture of sustainable development, like any culture, has formed an educational projection in relation to humanity. Mankind had to be brought up similar to a child, otherwise it could hurt itself in the future. There are no traces of "sustainable development" as an independent process in this "educational projection". An effective definition transformed into ecological standards of social behavior, including the socioecological forms of movement and settlement (Haraldsson, Ranhagen \& Sverdrup 2001) [11].

The question of the modalities of implementing a culture of sustainable development is of particular interest. The implementation of sustainable development culture is expressed in the limitation and self-restraint of production and consumption. Sustainable development culture takes on forms of prohibitions, conditions and compensations, not inherent to itself. Such forms of existence of sustainable development as a cultural of prohibitions and restrictions do not allow one to "see" the sustainable development as a proper culture, art or science in their positive, life-affirming forms.

In the social world international organizations took part in the implementation of sustainable development culture. This fact is important for the demarcation of sustainable development culture and science. Public organizations are not research institutions. The concept of sustainable development has been formed due to the social impulse of the Club of Rome's scientific model (Meadows, Meadows, Randers, Behrens, 1972) [12]. However, even with this "genetic form" sustainable development could not turn into a science. Science is not the same as culture, even in today's world where scientific knowledge "moves" the culture of mass consumption.

\section{Main Focus of the Article}

During the formation of sustainable development science the important question of "Why can't ecology 
study sustainable development?" comes to mind. Ecology and sustainable development intertwine axiologically. Both need to take care of humanity's "common home". However, scientific environmental objects are special biological objects negatively affected by human activity. This objectification of environmental studies is what defines the public support of ecology. Its popularity is based on the humanity's emotional sphere. There is also a slow shift in the emphasis of environmental studies. Changes in living objects caused by anthropogenic influence begin to take the shape the law. Modern scientific publications (i.e. «Methods in Ecology and Evolution») trace a special tendency in the study of evolutionary processes. Namely, the evolutionary processes are examined on the verge between evolution and degeneration. We affirm that sustainable development science should have its own research facilities and its own ontological picture.

The process of the formation of sustainable development science is not related to the formal definition of sustainable development, which originally was not intended to have a scientific form. Logical analysis of the content of «Our Common Future» captures a certain paradox in the definition: Sustainable development is development that meets the needs of the present without compromising the ability of future generations to meet their own needs (World Commission on Environment and Development, Our Common Future, 1987) [13]. We call this contradiction "the deferred consumption paradox". It created a strategy of self-restraint on the individual level of human existence in the advanced economies of the world. This circumstance is treated as a "brake" in the formation of positively-oriented science, which describes sustainable development.

At the same time, the impact of the aforementioned definition has created many practices of sustainable development in thirty years. These practical precedents require analysis, research and systematization from the standpoint of scientific knowledge. Thusly, objective circumstances for sustainable development science have been formed.

Sustainable development today is a sphere of activity that exists at the level of public and private practices. This is a positive objective condition. Sustainable development now bears a special meaning, which is "obvious" and one may not even realize it. This is an indication of the timeliness of the formation of science. Sustainable development purports to capture the non-productive public consciousness. It carries religious significance of the purification of consumption. This is a requirement of choice. In a world of action sustainable development science is preferable to religion. Science is the successor of philosophy and the last form of knowledge of sociodemanded facilities.
The task of forming a science involves a solving the issue of its name. It's decided by the means of syntax and semantics. The modality and object of a science are always reflected in its name. As for the science researching sustainable development, choosing from the science of "sustainable development", "science of sustainability", "science for sustainable development", we suggest the phrase "sustainable development science". The phrase "sustainable development science" shows the usage of systematic means as a foundation. "Sustainable development" in particular, is understood as a special process, which until now has existed regardless of scientific research. The emerging science follows this process, simultaneously forming its own component parts - the "model", "individual ontology", "means of expression", "research methodology," using the processes' materials for its own good.

The transition from a situation of social need for sustainable development science to the formation of sustainable development science in history begins with the "name" and ends with "scientific research programs".

The methodological and philosophical stage of the formation of sustainable development science - the definition of its constitutive method and object - are the most important. International science methodology has developed tools, which serve as a solution for the abovementioned problems of determining the method of science formation and its object (Shchedrovitsky, 1981) [14]. The theoretical "structure of a scientific subject scheme" presents a set of blocks. Completely filling such a set serves as evidence for the formation of science, science becoming a "machine of learning". The structure of the scientific subject includes "empirical data", "problems", "objectives", "languages", "models", "ontology", "theoretical knowledge", "methods". We relied on this methodological framework and put forward a question - which of the blocks serves as the main one during the intense process of science formation?

In this paper we affirm the following: creating sustainable development science requires, first and foremost, choosing the ontology of sustainable development science. Solving this issue also includes an indication of the method of forming sustainable development science itself.

Selecting the ontology for the formation of sustainable development science is linked to determining of what type of science sustainable development will be - a natural science or a technical science. The history of sustainable development attributes it to the sphere of human activity. Therefore, the science of sustainable development is a technical science (but not engineering), a social 
science (but not sociology), a science of life form preservation (but not biology). Of all types of modern ontology the "socio-technical ontology" corresponds to the essence of sustainable development the most. This is an ontology of "modern times." It was framed in the study of the processes of a) the formation of knowledge; b) development management (Shchedrovitsky, 2014) [15]. Its use in the forming of sustainable development science is defined by the common objects of sustainable development and management objects. Both types of objects are formed using the reflective method.

The question of ontology is quite controversial in the philosophy of science and philosophy as a field of knowledge. "Ontologies", viewed from the position of already formed sciences, act as "knowledge organization cores". From a philosophical position of shaping future subject entities, "ontologies" act as enveloping "pictures of the world." The name "sociotechnical" is created from two meanings. The first meaning is contained in the «socius» Latin root. It contains a reference to the fact that the process of sustainable development (as well as the management process) is formed by social activities, rather than natural systems. The second meaning is associated

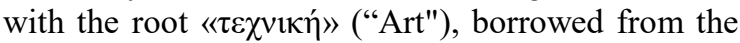
Greek language. It points to the subjective component of art needed to represent the freely unfolding process of sustainable development in knowledge.

Deciding on the issue of the ontology of sustainable development shifts it from the metaphysical plane to the plane of existing in the scientific subject. Schedrovitsky (2005) [16] indicates the requirements corresponding to the object applying for the status of an "ontological existence". Firstly, only objects that get portrayed in a certain pattern, either scientific or philosophical, acquire ontological status. Secondly, the representation of such an object in an image or knowledge is not enough. What is represented by an image or knowledge must still exist by itself, "according to its own objective laws." Sustainable development today satisfies the second requirement of an ontological existence. Compliance with the first requirement of the ontological existence is to be provided by sustainable development science.

Incorporating socio-technical ontology into the process of forming sustainable development science determines the method of formation sustainable development science. It is not reducible to filling the scientific subject blocks listed above. Analysis of the generation and use of socio-technical ontology allows us to seclude "reflective analysis" as a method of formation of sustainable development science.
The objectivity of this method is determined not only by socio-technical ontology, but also the need to implement the substitution of sustainable development practices by scientific knowledge forms.

Socio-technical ontology is based upon the principle of a reflexive relationship between the absorbed and absorbing areas. The ratio of consecution and formalization of phenomena and facts of one system in another system's facilities is built on what is known "reflection" principle (Lat. reflexio) in classical philosophy. The question of the development of philosophical concept of reflection in the methods of organization of scientific knowledge is presented in the work of Lefebvre (2003) [17].

Figure 1 shows the relationship between the spheres of activity of the practice of sustainable development and science. The practice of sustainable development referred to as the "absorbed sphere." The forming sustainable development science is qualified as the "absorbing sphere". Science "absorbs" the practical areas of activity in its reflective and analytical (later, in the research and model) relationship. We offer this as an ontological scheme for sustainable development science. The upper left quadrant indicates the independent existence of two unformed areas "sustainable development science" and "sustainable development practice". At the bottom there is a diagram of the reflective organization of sustainable development science on the basis of socio-technical ontology. The upper part shows the objective organization of sustainable development science the future goal.

Reflective analysis as a method for forming sustainable development science consists of two nonspecific characteristics.

The first characteristic is a functional one. "Substitution" - the main function of cognitive thinking, is carried out in the reflective analysis procedures. Groups of disparate phenomena are substituted for objective knowledge. The procedure of transition from study "material" to forms, that state and constitute the objects of science, is the first nonspecific characteristic of the reflexive method. It's this very characteristic that substitutes the practice materials of sustainable development for symbolic research forms. The reflective turn from spontaneous practice of sustainable development to the assignment of descriptive sustainable development scientific means (first and foremost, models and research means) is the procedure that constitutes sustainable development science. The aforementioned turn is denoted with an arching arrow with a "star" mark in Figure 1. 
Fig. 1: "Ontological scheme of sustainable development science"
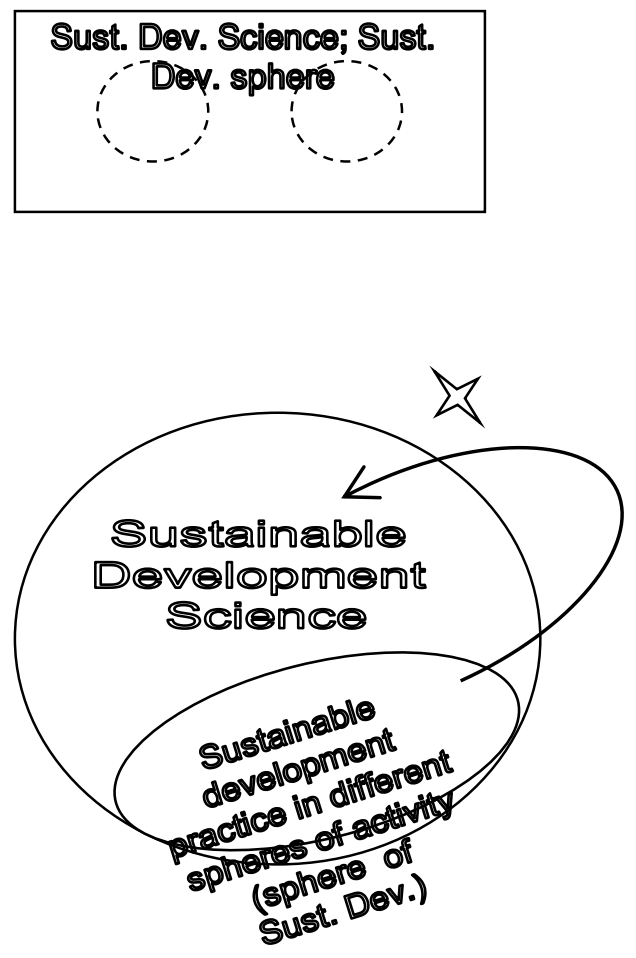

The second characteristic of the non-specific reflective analysis is its subjectivity. The meaning of this characteristic was emphasized by Kant, who considered reflection to be a way of forming concepts - the main means of philosophical thinking (Gardner, 1999 , p. 337) [18]. What is the role of subjectivity in the modern scientific knowledge forming processes? While describing the process of changing paradigms, Kuhn (1970) [19] pointed out the contradicting situations between the existing scientific paradigm and knowledge, accumulated in scientific research situations. We affirm that the "conflict" with current paradigm was revealed in the process of reflecting upon the contradiction between "fact and interpretation". The subjective factor in scientific knowledge emerges for the first time in this very context. Kuhn did not point out the value of reflection for the science formation, but he recorded the change in interpretation of knowledge during paradigm shifts. Formation sustainable development science is not a paradigm shift, but the creation of an original paradigm. But the emphasis defined by Kuhn is retained in this situation. The reflexive method's subjectivity came into science from philosophy. Today, the subjectivity of scientific knowledge is masked by two factors. The first is the methodical and instrumental equipment of science. The second is the transformation of science into a social institution. The latter circumstance, in our opinion, changes the
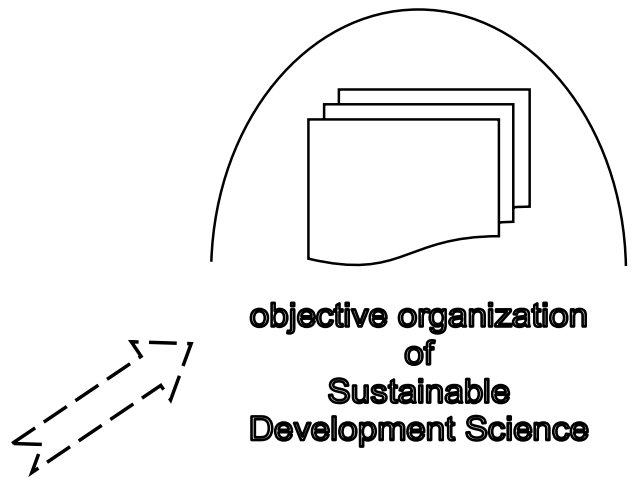

objective organization
of

Sustainable Development Science
Perspective of scientific knowledge from individual to collective. Collective reflection in the formation of a new science is different from the reflection of Kuhn's conflict: the contradictions of the factual area and the paradigmatic system. The researchers that support the creation of sustainable development science are working with a new object. The diversity of the levels of this object does not allow them to study it entirely. Therefore, reflective analysis is aimed at the formation of a mosaic mural of knowledge about the new object on the material of private research results and configuring them into a single academic unit.

\section{Main Focus of the Article}

In circumstances where a system of knowledge about the object of sustainable development is the ultimate goal of the science formed, the object of the future science can be "shown" through a) definition and b) attitude towards its image, its scheme.

This study attempts to determine the object sustainable development science:

The object of sustainable development (science) is the ratio between the "absorbed" and "absorbing" areas, expressed in the art of preserving the peculiarities of the absorbed area and their magnification (technical or otherwise). 
This definition of sustainable development science is a logical, "formal" one. We propose to correlate the definition of the object of sustainable development science with a particular image. That image is a diagram of "socio-technical systems" (Figure 2). The diagram of a simple socio-technical system is viewed as an "image" of the object of sustainable development science in the scientific picture of the world. The reflexive principle of the formation of sustainable development science itself is also denoted in the diagram's description (Schedrovitsky, 2006) [20]. The diagram shown in Figure 2 is an image of the relationship between the two systems. System "I" is the initial operation system, referred to as "natural". System "II" is the system reflecting on and studying system "I". System "II" covers system "I" by creating special symbolic forms. These forms are denoted by the black line between the two systems with an arrow colliding with the line. The arrow shows the relationship's reliance on the symbolic forms that emerged from the reflection of system "I" by system "II". "Symbolic forms" in the diagram of simple sociotechnical systems set the place of sustainable development science, reflecting and systematizing natural achievements of sustainable development. The left side arrow indicates the relationship between design and organization, which sustainable development science may take in the case of its functional expansion. The relationship between research and the possibility of organizing sustainable development allows us to label system "II" as "artificial" in relation to the system "I".

Using the "simple socio-technical system diagram" to illustrate the nature of the objects of sustainable development science requires a reservation. This diagram was used to describe the structure of complex objects in management science, the formation of symbolic forms such as "projects" and "programs". In sustainable development science the "diagram of simple socio-technical systems" is used to produce symbolic forms of the research, not designed, kind "scientific knowledge" of the natural characteristics of the objects of sustainable development. The main categorical research "fields" in the formation of the object of sustainable development science are: "relation", "peculiar features", "areas", "conservation" and "magnification".

\section{Fig. 2: "Socio-Technical System"}

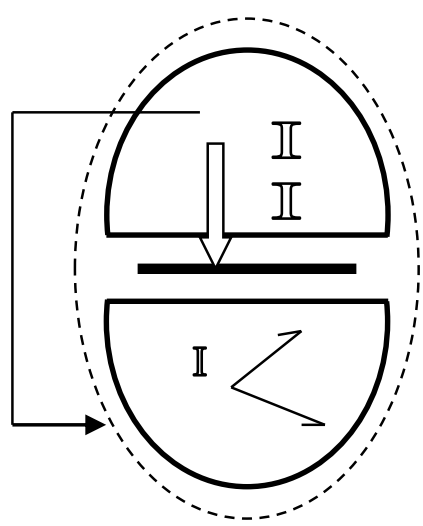

Fig. 3: "Science and Practice of Sustainable Development"
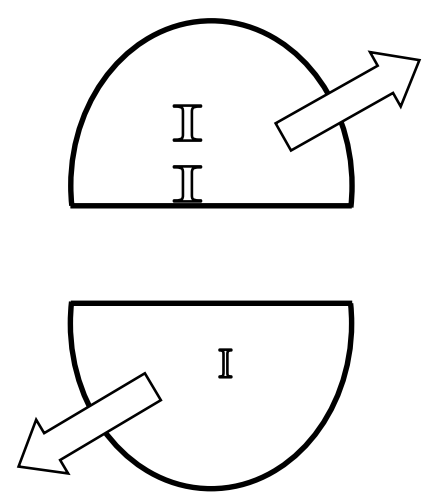
We make notice of the error in the use of the sociotechnical system diagram. This systemic diagram is not a diagram of the object of sustainable development. However, all the results of the study of objects of sustainable development can be correlated with the "simple diagram of socio-technical systems." This diagram allows us to distribute subject knowledge about the objects of sustainable development in accordance with the types of the systems included: natural and artificial. We come to a conclusion about the systemic origin of the objects of sustainable development. We make another reservation. It allows to distinguish sustainable development science from management activity. Management activity uses scientific knowledge. Sustainable development science does not manage, it cognizes. It explores and describes the laws of sustainable development, creates sustainable development models. But first and foremost, science works on its own means of expression, it develops itself, not the areas it covers. Sustainable development science examines the scope of knowledge as its absolute limit.

Creating sustainable development science is using reflection in relation to the innovations that appear in the various fields of practice as a "trace of sustainable development". This is a description of these innovations as models, research methods, private ontologies, problems and challenges. The scientific subject diagram serves as an integrating "symbolic form".

Reflective analysis used as a method and ontological principle is the foundation in building sustainable development science on the material of situational practices. Now all that's need is to distinguish the areas that contain the socio-industrial sustainable development situations.

Currently, we have made the selection of subject areas, allowing the reflective transition from practices to scientific knowledge. "Biosphere reserve" and "urban agglomeration" can be considered the first investigated practical spheres of sustainable development. The list is open.

Thus, reflection serves as a temporary connection of the forming sustainable development science and the various practices of sustainable development. Reflective analysis forms sustainable development in the scientific means. Two components of sociotechnical systems in the diagram in Figure 2 are "linked" together. In the science formation diagram in Figure 1 the two areas are not in a "clinch". Sustainable development science and practices of sustainable development can (despite the reflexive communication factor that creates scientific forms) move on a free path (Figure 3 ).
We draw attention to the difference in the definition of the object of sustainable development science and the description of socio-technical systems diagram. The object of sustainable development science appears in the relationship between the "areas" of scientific and practical activities. The diagram of socio-technical systems implies that these relations are already established and are systemic in character. Relations become permanent ties between research and provision. We affirm that the definition of the object of sustainable development science expresses the first step in the formation of science.

Describing reflection as a method of shaping the contents of sustainable development science does not mean that this method is the only one. Reflective analysis solves the special problem of transitioning from activity practices to the forms of knowledge. The reflective transition practice involves a subjective component of scientific cognition. It's defined by substantive means possessed by the researcher. The object of sustainable development will be presented one way in economic means and another way the mean of preventive technology organization.

"Subjective" characteristics in the study are replaced by objectifying reflection and designing during the next stage. A configured object of study emerges during this process.

\section{Conclusion}

Creating sustainable development sustainable is a joint activity of history and scientific research teams. The objectification of the existence of the sustainable development process is a methodological problem to be solved with both the philosophical and scientific methods. The metaphysical status of sustainable development should be changed. The authority of scientific knowledge makes this task possible.

In sustainable development we set the task of developing the scientific paradigm. To date, the culture of sustainable development included: a) the definition of sustainable development; b) common human sense (the task of preserving the planet for future generations); c) regulations that limit all activities that deteriorate the environment. However, the cultural paradigm of sustainable development does not contain any research forms - knowledge about the object of sustainable development.

We consider reflective analysis to be a non-specific method in the formation of science. The choice of this method is defined by its philosophical reliability. Reflective analysis may provide several functions in the formation of science. The first function is the substitution of one form of content with another knowledge. The second function is providing individual cognitive activity when confronted with 
the problem of its implementation. The third function is the development of the concept of "object" in collective scientific activity.

We affirm that sustainable development science is necessary. Three "things" emerge as a result of "sustainable development" turning from concept to science. The first "thing" is the area of the objects of sustainable development. We will be able to see objects of sustainable development through the "glasses" of scientific knowledge. The second "thing" is the long-term research programs. They allow us to outline a new field of systematic relations in the study of configured objects of sustainable development. Namely, the relationships between different forms of life and activity in the world. The third "thing" is the modern research teams reconstructing the philosophical ways of knowing in their work.

\section{Acknowledgment}

The research is implemented with financial support of Russian Foundation for the Humanities. Project "Biospheric reserve: systemic justification of processes of social, economic, ecological development" No. 16-02-00037.

\section{References}

1- Le Roy, E. (1931). Les origines humaines et l'évolution de l'intelligence. Paris Boivin \& Cie, Paris.

2- Teilhard, C. (1959). Phenomenon of man. Harper: New York.

3- Vernadsky, V.I. (1944). A few words about the Noosphere. Success of modern Biology, 18(2), 49-93 (in Russian).

4- Stahl, B.J. (1974). Vertebrate History Problems in Evolution. Dover: New York.

5- Lewin, R. (1981). Bones of mammals' ancestors fleshed out. Science, 212, p. 1492.

6- Rip, A. (2006). Folk Theories of Nanotechnologists. Science as Culture, 15(4), 349-365.

7- Peierls, R. (1980). Model-making in physics. Journal Contemporary Physics, 21(1), 3-17.

8- UNESCO (1996). Biosphere reserves: The Seville Strategy and Statutory Framework of the World Network. UNESCO: Paris.

9- Porter, M.E. (1998). On Competition. Harvard Business School Press: Boston.

10- European commission (2007). Commission plans legislative framework to ensure the $\mathrm{EU}$ meets its target for cutting CO2 emissions from cars. Retrieved from http://europa.eu/rapid/press-release_IP-07155_en.htm\#fn1

11- Haraldsson, H.V., Ranhagen, U., \& Sverdrup, H. (2001). Is Eco-living more sustainable than conventional living? Comparing sustainability performances between two townships in southern Sweden. Journal of Environmental Planning and Management, 44(5), 663-679.

12- Meadows, D.H., Meadows, D.L., Randers, J., \& Behrens, W.W. (1972). The Limits to Growth. Universe Books: New York.

13- United Nations (1987). Report of the World Commission on Environment and Development Our Common Future. Chapter 2: Towards Sustainable Development / Merging Environment and Economics in Decision Making.

14- Shchedrovitsky, G.P. (1981). Principles and general scheme of the methodological organization of system-structural research and development. System studies methodological problems. Science: Moscow, 193-227 (in Russian).

15- Shchedrovitsky, G.P. (2014). Organizational managerial thinking: ideology, methodology, technology. Art. Lebedev Studio: Moscow (in Russian).

16- Shchedrovitsky, G.P. (2005). Thinking. Understanding. Reflection. Legacy MMK: Moscow. (in Russian).

17- Lefebvre, V.A. (2003). Systems, comparable with the researcher on perfection. Kogito-center: Moscow. (in Russian).

18- Gardner, S. (1999). Kant and the Critique of Pure Reason. Routledge: Philosophy Guidebook.

19- Kuhn, T.S. (1970). The Structure of Scientific Revolutions. THE UNIVERSITY OF CHICAGO PRESS, LTD.: LONDON.

20- Shchedrovitsky, G.P. (2006). Sign and activity. Vostochnaya Literatura: Moscow (in Russian). 